\title{
Enhancement of chip breakability of aluminium alloys by controlling the solidification during direct chill casting
}

\author{
Nilam S. Barekar ${ }^{1,2, *}$, Ivan Skalicky ${ }^{2,3}$, Carla Barbatti ${ }^{2,4}$, Zhongyun \\ Fan $^{1}$, Martin Jarrett ${ }^{2,5}$
}

${ }^{1}$ BCAST, Brunel University London, Uxbridge, Middlesex, UB8 3PH, United Kingdom

${ }^{2}$ Constellium University Technology Centre, Brunel University London, Uxbridge, Middlesex

UB8 3PH, United Kingdom

${ }^{3}$ Constellium Extrusions Decin s.r.o., Ustecka 37, 40535 Decin V, Czech Republic

${ }^{4}$ Constellium, Parc Economique Centr'alp, CS10027, Voreppe, 38341 cedex, France

${ }^{5}$ Constellium UK Ltd, Grenville Court, Britwell Road, Burnham, Bucks SL1 8DF, United

Kingdom

*Corresponding Author: Dr. Nilam S. Barekar, Phone: +44 1895 268529,

Email:nilam.barekar@brunel.ac.uk

\section{Abstract:}

Refinement and uniform dispersion of the free machining elements within the matrix is always desirable for aluminium billets produced by direct chill (DC) casting. The conventional grain refiner addition cannot ensure uniformity of microstructure and homogeneous distribution of insoluble or intermetallic phases. Melt conditioned directchill (MC-DC) casting is a key technology for producing uniform microstructure and refinement of secondary phases. This physical approach combines conventional vertical direct chill (DC) casting with a high shear device directly immersed in the sump for in situ microstructural control. Increased heat extraction rate due to forced convection, a larger temperature gradient at the solidification front and a shallower sump contribute to fine equiaxed dendritic grains with fine dendritic arm spacing that favor the fine and uniform distribution of second phase particles in the as-cast billet giving rise to much improved machinability. 
Keywords: Direct chill casting, Melt Conditioning, Grain Structures, Extrusion, Machinability

\section{Introduction:}

Chip control in machining of metals has attracted strong interest due to its importance in automated machining operations. Grade "A" machinability performance of metals or alloys characterised by short, broken chips and smooth product surfaces is strived for in order to guarantee high tool feed rates and spindle speeds in connection with low cycle times and reduced machine downtimes for cleaning [1]. In this regard, free machining alloys are well known in the art from many decades [2]. Typical free machining alloys contain heavy elements, such as lead $(\mathrm{Pb})$, bismuth $(\mathrm{Bi})$, tin $(\mathrm{Sn})$, indium (In) or cadmium (Cd), to minimise the chip size and hence, increase the machinability. Generally, chip breaking alloying elements have to show the following properties: (i) these elements are insoluble in solid aluminium, (ii) have lower melting points in comparison to aluminium, (iii) do not form intermetallic compounds with aluminium or other alloying components, and (iv) have lower hardness than the aluminium matrix. $\mathrm{Pb}, \mathrm{Bi}, \mathrm{Sn}, \mathrm{Cd}$, In meet all or most of these requirements [3]. These elements form low melting compounds that readily melt or soften due to the frictional heat created during machining. More specifically, at the point of contact between the machining tool and the material, the temperature can reach values as high as $350^{\circ} \mathrm{C}$ [4]. As a result of these changes, breakage occurs, chips are formed and material removal is enhanced. It has been further discovered that the simultaneous presence of two of these elements is more productive of an improvement in free machining than that caused by the presence of the same total amount of a single free machining element [2]. This was attributed to their low melting eutectic phase. Over the past four 
decades, there has been an ever-increasing global movement to reduce or eliminate lead due to its toxicity and hazardous waste disposal problem [5].

When using free machining constituents having higher melting points than the eutectic compounds of heavy elements noted above, material removal results from a different mechanism. At the point of contact with machining tool, void formation occurs as a result of the different flow characteristics between the base aluminium and the high melting point constituents. This void formation then causes breakage and subsequent chip formation [6]. The influence of the second phase particles or intermetallics in commercial Al alloys on chip breakability was investigated by Kamiya et al. [7]. A linear relationship was observed between the chip-breaking factor (number of chips per 100 g) and volume fraction $\left(V_{f}\right)$ of the second phase particles in the alloys. The second phase particles of $\mathrm{Al}_{2} \mathrm{Cu}(400-700 \mathrm{HV})$ and $\mathrm{Si}(900-1100 \mathrm{HV})$ in the aluminium alloys were fractured during the machining process. It was estimated that the fractured second phase particles acted as the cause of chip breaking. Zedan et al. [8] have reported the effect of iron intermetallics such as $\alpha-\mathrm{Fe}\left(\mathrm{Al}_{12}(\mathrm{Fe}, \mathrm{Mn}, \mathrm{Cu})_{3} \mathrm{Si}_{2}\right), \beta-\mathrm{Fe}$ ( $\mathrm{Al} 5 \mathrm{FeSi})$ and sludge $\left(\mathrm{Al}_{15}(\mathrm{Fe}, \mathrm{Mn}, \mathrm{Cr})_{3} \mathrm{Si}_{2}\right)$ on the machinability of heat-treated $\mathrm{Al}-\mathrm{Si}$ alloys. It was claimed that formation of the $\alpha-F e$ intermetallic with more rounded Chinese script morphology within $\alpha-A l$ dendrites improves overall alloy machinability. This was attributed to the improvement of matrix homogeneity via hardening of the soft $\alpha-\mathrm{Al}$ dendrites and a greater stability of $\alpha$ - Fe within the matrix during machining due to atomically rough interface. The sludge phase having high hardness values (500 $-900 \mathrm{KHN}$ ), a high melting point and a high specific gravity compared to the matrix, resulted in excessive tool wear and damage to cutting tools during machining.

It has been emphasised that effect of second phase particles (either soft or hard) on improving machinability could be further enhanced by distributing them relatively 
homogeneously throughout the solid matrix [2]. A sufficiently fine distribution (5 - 10 $\mu \mathrm{m})$ is preferred so that free machining occurs throughout the work piece [9]. Despite of these suggestions, studies of the influence of microstructure on machinability are relatively scarce to date. It is apparent that there is need for a more in-depth understanding of the effects of the microstructure on machinability of the cast and subsequently extruded components. In response to this need, the present investigation is focused on controlling the size and distribution of second phase particles in the as-cast microstructure. This has been accomplished through in situ microstructural control by using high shear device [10] for treating liquid aluminium during direct chill (DC) casting. The high shear DC casting process can produce Alalloy ingot with fine and uniform microstructure without using any grain refiner addition. Finer and homogeneous distribution of second phase particles was observed due to finer dendritic arm spacing. Such melt conditioned direct chilled (MC-DC) billets were further extruded to round bars by hot extrusion. Machinability tests were performed on these round bars and the results were correlated with the microstructure. Efforts have been made to understand the microstructural evolution during the melt conditioning direct chill casting. Experimental results are discussed in the context of the current understanding of the subject.

\section{Experimental Procedure:}

\subsection{Casting experiments and examination of billets}

Round billets of $152 \mathrm{~mm}$ diameter were cast in a pilot DC casting facility at the Advanced Metal Casting Centre in Brunel University London. The schematic of DC caster and the position of the high-shear device is shown in Figure 1. The DC caster consists of an electrical resistance tilting furnace (capacity up to $350 \mathrm{~kg}$ of liquid 
aluminium); a launder that make up a delivery system; two hot-top moulds fitted into a water box; a hydraulic movement mechanism for ingots ( a maximum length of 2000 $\mathrm{mm}$ ); a displacement sensor for measuring the casting length and speed; a submersible water pump and a system of pipes and valves enabling the water-flow rates from 1 to $3 \mathrm{l} / \mathrm{s}$ for two moulds. The process parameters such as melt temperature, water flow rates, casting speed are controlled and recorded. The operation is semiautomatic, with a manual start-up phase and automatic steady state casting. A unique feature of the set-up is a possibility to change process parameters during a single drop. Two types of experiments were performed. Table 1 shows the process details of these experiments.

The casting started with the alloy of the nominal compositions shown in the table 1. A steady state was reached after a sufficient length of the billet was produced $(\sim 300$ $\mathrm{mm}$ ). Two set of experiments were carried out; one with the standard addition of grain refiner ( $1 \mathrm{~kg} / \mathrm{Mg}$ i.e. $1 \mathrm{~kg} / \mathrm{tonne})$ and other with high shear melt conditioning without any grain refiner addition. Two different commercially available grain refiner were added to the investigated alloys, namely, in a form of Al-5\% Ti-1\% B rod for AA2011 and $\mathrm{Al}-3 \% \mathrm{Ti}-1 \% \mathrm{~B}$ rod for $\mathrm{AA} 6050$. For melt conditioning, a rotor-stator device was employed for intensive shearing of the melt. A more detailed description of fluid flow in the high shear device can be found elsewhere [11]. The main advantages of the high shear device include the enhancement of kinetics for in situ chemical reactions, homogenisation of chemical composition and forced wetting of usually difficult to wet solid particles in the liquid metal. Moreover, the high shear device can be used for physical grain refinement by dispersing naturally occurring oxides [10]. The position of high shear device in the hot top was adjusted in such a way that the melt temperature at the bottom of the stator is about $3-4{ }^{\circ} \mathrm{C}$ above the liquidus temperature of the casting 
alloy. The melt shearing was carried out at $2000 \mathrm{rpm}$. To reveal the real sump profile for understanding the solidification mechanism, liquid $\mathrm{Zn}$ was added during casting trials of AA2011 and the position on the casting length was noted. The direct chill cast billets with grain refiner addition and melt conditioning are referred as DC-GR and MCDC, respectively.

Cast billets were cut by sawing at transverse sections from the steady-state stage. The sawed slices were then cut to smaller samples as shown in figure 2, which were then ground and polished. The secondary phase particles were analysed using a Zeiss Supra 35 field-emission gun (FEG) scanning electron microscope operating at $20 \mathrm{kV}$. To observe the 3D morphology of the intermetallics, samples were deep-etched using an aqueous solution containing 15 vol. $\% \mathrm{HCl}$. Grain structure was studied under cross-polarized light after anodizing the samples in a $3 \% \mathrm{HBF}_{4}$ aqueous solution. Structure parameters such as dendritic arm spacing and grain size were measured on the micrographs of half radius samples using the random linear intercept technique. With reference to the position of zinc addition, the billets were longitudinally sectioned in the centre. A $10 \% \mathrm{NaOH}$ solution and a nital cleaning agent were used for macro etching to reveal the real sump profile during DC-GR and MC-DC casting.

\subsection{Downstream processing, machinability and mechanical testing}

AA2011 as-cast billets were extruded to $33 \mathrm{~mm}$ diameter round bar by hot extrusion (1.6 Mg extrusion press at Constellium University Technology Centre (UTC), Brunel University, London, UK) and were hardened by cooling with water immediately after extrusion. The rods were then solutionised, stretched and aged to obtain sample material in temper T8. AA6050 as cast billets were homogenised prior to extrusion into 
$33 \mathrm{~mm}$ diameter round bar by hot extrusion followed by water cooling. The rods were aged to obtain sample material in temper T6.

For the machinability test, turning operation was performed on an automated lathe machine using a CCGX 09 T3 04-AL 1105 cutting insert at a cutting speed of $2.35 \mathrm{~m} / \mathrm{s}$ for a depth of cut of $2 \mathrm{~mm}$ and with cutting fluid. A sensitive and quantitative evaluation method to determine the chip breakability by measurement of the chip weights [12] is used. The chips obtained from longitudinal turning were compared by weight of chips obtained for different as-cast variants for the same set of cutting parameters. For each variant, three set of 200 randomly collected chips were weighed. The tensile tests were conducted for at least 4 samples using an Instron 5559 universal electromechanical testing machine according to ASTM E8 with dual rate $\left(2.5 \times 10^{-4}\right.$ strain/s to $1 \%$ strain and $6.6 \times 10^{-3}$ strain/s to failure).

\section{Results and Discussion:}

\subsection{As-cast microstructure}

The microstructures from the edge, half radius and centre of AA2011 and AA6050 cast under different melt treatments are depicted in figures 3 and 4, respectively. The billets produced by commercial practice i.e., by addition of grain refiner show dendritic structures near the edge and mixed (dendritic and globular) structures near the centre. On the other hand, the billets produced by melt conditioning high shear technology show relatively uniform microstructure with equiaxed dendritic grains from the edge to the centre. Fine equiaxed dendritic grains with fine dendritic arm spacing at the half radius of the MC-DC sample are clearly visible compared to the DC-GR sample. Unlike the DC-GR sample, the presence of large globular floating grains was not observed in the case of the MC-DC billets at the centre. Table 2 summarizes the grain size and dendritic arm spacing (DAS) at the half radius of DC-GR and MC-DC billets of AA2011 and AA6050. The local cooling rate estimated from DAS [13] is also included in the Table 2. 
In DC casting, melt is poured into an open-ended, water-cooled mould with the bottom closed by a starting block. A shell is formed upon contact with the mould (primary cooling). The starting block is then pulled downwards at a specified casting speed $\left(V_{\text {cast }}\right)$. A water jet cools the surface of the shell when it exits the mould (secondary cooling). The billet is pulled at the casting speed to the required length while melt is continuously poured in the mould at a rate that keeps the melt level in the hot top constant [14]. A fine and uniform microstructure is desirable for billets that are produced by DC casting. The grain morphological evolution during the solidification process depends on the growth mode defined by solid/liquid interface stability, which can be understood by the Mullins-Sekerka criterion [15]. Based on the Mullins-Sekerka criterion, a high nucleation rate by inoculant particles and a low thermal gradient in conventional DC casting with grain refiner favor granular growth. The thermosolutal convection in the slurry zone is relatively low compared with the forced convection during MC-DC casting under a high shear rate. A coarse dendritic arm spacing develops after interfacial instability occurs whilst a fine dendritic arm spacing develops in the deep mushy zone. In conventional DC casting, the cooling rate decreases as the centre is approached. The non-uniform cooling rate across the cross section of the billet results in the variation of the grain size. General coarsening of the structure in the central portion of the billet can be associated with a longer solidification time and correspondingly slower total cooling rate in this region and with a wider region of relatively stagnant flow where grains have ample opportunity to grow and coarsen [16]. The possible reason for local dendritic arm spacing refinement is in the local decrease of the solidification time in this part of the billet. Floating grains form where there is a longer time for their growth due to their trajectory within the slurry zone and their transport by melt flow towards the centre of the billet where they settle [16]. 
In MC-DC casting, a rotor-stator mechanism (the high shear device) is immersed into the sump. The rotor rotates at high speed in a cylindrical stator comprising many small holes. The high shear rate is due to the high speed of the rotor and the small gap between the stator and the rotor. The negative pressure that is generated by the rotor blades sucks the melt upwards and forces flow out of the stator holes. As a result, a turbulent flow with high shear rate is generated in the rotor stator mixer [17]. The advantage of MC-DC casting is that it provides both dispersive and distributive mixing in the sump, while keeping the melt surface relatively stable. The region of intense mixing around the mixer is toroidal [18] and is denoted as a pseudo-cavern by the literature [19]. In MC-DC casting, grain nucleation is also initiated in the slurry zone, however, which is characterized by a high thermal gradient and high undercooling compared to conventional DC casting, due to an enhanced rate of heat extraction by the intensive forced convection. This results in a very early breakdown of spherical growth and therefore, fine equiaxed dendritic grains develop [20]. The grain refinement observed in the case of MC-DC billets is attributed to the effective dispersion of naturally occurring oxides that can act as nucleating sites and thus enhance heterogeneous nucleation during the solidification. Intensive melt convection in the sump enhances the kinetics for both mass and heat transfer resulting in uniform temperature and compositional fields in the slurry zone.

\subsection{Sump profile}

Figure 5 represents the real sump profiles (darker part) of DC-GR and MC-DC AA2011 billets cast at $2.5 \mathrm{~mm} / \mathrm{s}$. A relatively steeper and deeper sump was observed during DC-GR casting. The sump does not change its shape and position during the steady stage DC casting. The dimensions and geometry of the sump are determined by the temperature distribution that is the product of heat transport in and out of the system. 
Heat input is the energy introduced into the system by the melt (temperature and specific heat of the liquid) and generated during solidification (latent heat of solidification and the specific heat of the solid). Heat extraction occurs by convection of the melt in the sump; by conduction of heat through liquid, semi-solid, and solid part of the billet; and by convection of cooling water inside the mould and at the billet surface [16]. The solidification rate (the velocity of the solidification front, $V_{s}$ ) depends on the casting speed and the angle $\left(\propto_{n}\right)$ between the billet axis and the normal to the solidification front by the following equation [21].

$$
V_{s}=V_{\text {cast }} \times \cos \propto_{n}
$$

From equation (1) and figure 5, there is a relatively lower solidification rate during DCGR casting at about half-radial position, where the solidification front is the steepest [22]. During MC-DC casting, due to intensive forced convection, the enhanced mass transfer leads to an increased heat extraction rate in the sump. Thus, the cooling rate in the slurry zone of MC-DC casting is higher compared to that of conventional DC casting. The uniform distribution of cooling rate across the cross-section enables a uniform microstructure across the whole transverse section. The results of the numerical modelling of MC-DC casting [23] also show a larger temperature gradient at the solidification front, a shallower sump and increased heat extraction rate due to forced convection in the sump contributing to a finer, uniform grain structure in the ascast billet. The solidification velocity was calculated from the sump profiles about half radius for $2.5 \mathrm{~mm} / \mathrm{s}$ casting speed and found out to be $1.9 \pm 0.005 \mathrm{~mm} / \mathrm{s}$ and $1.65 \pm$ $0.025 \mathrm{~mm} / \mathrm{s}$ for MC-DC and DC-GR casting respectively. The higher value of solidification rate at half radius for MC-DC casting results in finer equiaxed dendrites with finer arms spacing. 


\subsection{Size and distribution of secondary phases}

Scanning electron microscopy carried out on the AA2011 MC-DC half-radius sample shows improvement in the dispersion and considerable refinement of insoluble soft phase particles compared to the conventional DC-GR sample (figure 6). The observed droplet number density at the half radius of DC-GR as-cast sample shows $142 \pm 14$ droplets $/ \mathrm{mm}^{2}$, whereas the corresponding droplet number density for MC-DC as cast sample is $210 \pm 36$ droplets $/ \mathrm{mm}^{2}$. Figure 7 gives the SEM images showing the 3D morphology of the intermetallic phases in AA6050 DC-GR and MC-DC deep-etched samples. Shear is a very important phenomenon in melt conditioning. The liquid shear rate is responsible for the dynamics of agglomeration and breakage of the dispersed phases. A high level of shear rate $\left(10^{5} \mathrm{~s}^{-1}\right)[17]$ is expected in the close vicinity of the mixing head (i.e. the gap between the rotor and the inner surface of the stator). The shear rate as the melt flows out of the holes of the stator was calculated as $10^{4} \mathrm{~s}^{-1}$ [17] which further contributes to the dispersion of insoluble phases. The solidification process is characterized by a high thermal gradient during MC-DC and this results in a fine equiaxed grain with fine dendritic arm spacing. Therefore, the greater grain boundary area per unit volume leads to thinner liquid in dendritic arm spacing and a large number of isolated channels. Consequently, comparatively fine, short, less connected and uniformly distributed second phase particles (insoluble / intermetallic phases) were observed in the case of the MC-DC sample. The representative microstructures of the extruded T8 AA2011 DC-GR and MC-DC samples near the edge of the bar where machining trials were performed are depicted in Figure 8. MCDC sample shows improved dispersion and considerable refinement of insoluble soft phase particles compared to the conventional DC-GR sample. Figures 9 and 10 show 
the size distribution of insoluble droplets and intermetallics phases in extruded T8 AA2011 and extruded T6 AA6050, cast respectively with grain refiner addition and melt conditioning. The microstructural analysis of extruded samples clearly show that the desirable as-cast structural features have similar trend (i.e. finer secondary phase particles in case of MC-DC) even after extrusion. This is very advantageous for improving machinability and mechanical performance of the extruded solid bars.

\subsection{Machinability and tensile properties}

Chip breakability in terms of number of chips per $100 \mathrm{~g}$ is shown in figure 11 for extruded T8 AA2011 and extruded T6 AA6050. This indicator of machinability for the AA2011 MC-DC specimen is approximately $50 \%$ higher than for the AA2011 DC-GR specimen. This illustrates the ability of MC-DC casting to generate a higher number of chips per $100 \mathrm{~g}$ during machining. A large number of chips for MC-DC indicates that a relatively smaller chip size was being produced during machining compared with DC-GR. Improvement in machinability for MC-DC AA6050 is comparatively low (approximately $6 \%$ ) over DC-GR AA6050. Nevertheless, $6-7$ long $(4-5 \mathrm{~cm})$, continuous, curly chips were formed in the case of the DC-GR sample, which were not taken into account while counting 200 chips. No such long continuous curls were formed during machining of the MC-DC sample. Figure 12 shows the comparison of tensile properties of AA6050 cast using DC-GR and MC-DC methods. Compared with the conventional DC-GR process, the MC-DC process provides samples with a slightly higher ultimate tensile strength (UTS) and elongation. Yield strength (305 $\pm 3 \mathrm{MPa})$ and UTS (412 $\pm 2 \mathrm{MPa})$ levels of the MC-DC AA2011 specimens were similarly close to the DC-GR AA2011 specimens with slightly higher (12\%) elongation. It is well known that both the structure and properties of material are extremely sensitive to the fabrication technique. Insoluble phases interrupt the homogeneous alloy matrix 
contributing to better machinability of the material. These low melting compounds readily melt or soften due to the frictional heat created during machining. The finely dispersed low-melting soft phases assist the formation of short broken chips regardless of where the tool contacts the article being machined. During turning, extensive plastic deformation occurs in the shear plane, which causes the breaking of less ductile materials [3]. Furthermore, because there is a different hardness and different thermal expansion of the secondary phases and the matrix, the secondary phases could act as a source of stress concentration, leading to a crack formation [6]. Continued application of the machining forces creates new voids and propagates existing voids until the voids interconnect and machining debris is formed. The significant refinement and uniform distribution of the secondary phases within the matrix achieved by the MC-DC process directly affect the properties and lead to improved performance during machining.

\section{Conclusions}

The influence of intensive melt shearing during direct chill casting was investigated from microstructure-property correlation point of view. The microstructural analysis indicates the positive impact of melt conditioning in obtaining fine equiaxed grains with finer dendritic arm spacing. Increase in grain/liquid surface area per unit volume, results in finer and less connected insoluble phases and intermetallics. The results clearly demonstrate that the MC-DC technique offers better machinability than the conventional DC-GR technique in terms of higher number of chips per $100 \mathrm{~g}$. The size and distribution of the chip breaking particles are important for the machinability. These facts suggest that the chip breakability of Al alloys is expected to improve by the refinement and dispersion of second phase particles achieved through melt conditioning. 


\section{Acknowledgment:}

The authors acknowledge the financial support of the UK Engineering and Physical

Science Research Council (EPSRC Grant: The Future Liquid Metal Engineering Research Hub, under grant number EP/N007638/1) and Constellium, Ltd.

\section{Data Availability}

The raw/processed data required to reproduce these findings cannot be shared at this time due to legal reasons and forms part of an ongoing study.

\section{References:}

[1] S. Koch, H. Antrekowitsch, Free-cutting aluminium alloys with tin as substitution for lead, BHM Berg- und Hüttenmännische Monatshefte 153 (7) (2008) 278 - 281.

[2] L. W. Kempf, W. A. Dean, Patent No. 2076575 (1937).

[3] A. Smolej, B. Breskvar, M. Sokovic, V. Dragojevic, E. Slacek and T. Smolar. Properties of aluminium free-cutting alloys with tin, Part 1, Aluminium 78 (2002) 284 $-288$.

[4] J. Faltus, M. Karlík, P. Haušild, Properties of free-machining aluminium alloys at elevated temperatures, In: Weiland H., Rollett A.D., Cassada W.A. (eds) ICAA13 (2012) Pittsburgh. Springer, Cham. 873 - 878.

[5] S. Sircar, A free machining aluminium alloy containing bismuth or bismuth-tin for free machining and a method of use. Pub. No. WO 01/06027 A1 (2001).

[6] S. Sircar, Free machining aluminium alloy with high melting point machining constituent and method of use. Patent No. 6416598 (2002).

[7] M. Kamiya, T. Yakou, Role of second-phase particles in chip breakability in aluminium alloys, Int. J. Machine tools and Manufacture 48 (2008) $688-697$.

[8] Y. Zedan, F. H. Samuel, A. M. Samuel, H. W. Doty, Effects of Fe intermetallics on the machinability of heat-treated Al- (7-11) \% Si alloys, Journal of Materials Processing Technology 210 (2010) $245-257$.

[9] S. Sircar, Free-machining aluminium alloy and method of use. Patent No. 6315947 (2001).

[10] Z. Fan, B. Jiang, Y. Zuo, Apparatus and method for liquid metals treatment, Patent No. US 2013/0228045 A1.

[11] J. Patel, Y. Zuo, Z. Fan, Liquid metal engineering by application of intensive melt shearing, in M. J. M. Krane, A. Jardy, R. L. Williamson, J. J. Beaman (Eds.), 
Proceedings of the 2013 International Symposium on Liquid Metal Processing and Casting, TMS, Austin, Texas (2013) $291-299$.

[12] H. Du, A. Karasev, N. Stavlid, T. Bjork, S. Lovquist, P. Jonsson, Using chip weight distribution as a method to define chip breakability during machining, Procedia Manufacturing 25 (2018) 309 - 315.

[13] Spear, R. E., Gardner, G. R., 1963. Dendrite Cell Size. Transaction AFS. 71, $209-215$.

[14] J.H. Grandfield, D.G. Eskin, I.F. Bainbridge, Direct-chill casting of light alloys: science and technology, John Wiley \& Sons, Hoboken, NJ (2013) 30 - 55.

[15] W. W. Mullins, R. F. Sekerka, morphological stability of a particle growing by diffusion or heat flow, Journal of Applied Physics 34 (1963) 323 - 329.

[16] D. G. Eskin, Physical metallurgy of direct chill casting of aluminium alloys, CRC press, Taylor \& Francis group, United States (2008) 79 - 124.

[17] M. Tong, J. B. Patel, I. Stone, Z. Fan, D. J. Browne, Identification of key liquid metal flow features in the physical conditioning of molten aluminium alloy with high shear processing, Computational Materials Science 131 (2017) 35 - 43.

[18] A. Dybalska, D. G. Eskin, J. B. Patel, Validation of the physical simulations of a stirred molten metal using particle image velocimetry data, JOM 70 (2018) 1256 1260.

[19] L. Doucet, G. Ascanio, P. A. Tanguy, Hydrodynamics characterization of rotorstator mixer with viscous fluids, Chemical Engineering Research and Design 83 (2005) 1186 - 1195.

[20] H.-T. Li, J. B. Patel, Z. Fan, Solidification mechanisms of melt conditioned directchill (mc-dc) casting, In Proceedings of the $6^{\text {th }}$ Decennial International Conference on Solidification Processing, 25 - 28 July (2017) 137 - 140

[21] V. A. Livanov. In Proceedings of the First Technological Conference of Metallurgical Plants of Peoples' Commissariat of Aviation Industry, Moscow: Oborongiz (1945) 5 - 58.

[22] V. A. Livanov, R. M. Gabidullin, V. S. Shepilov. Continuous Casting of Aluminium Alloys, Moscow: Metallurgiya (1977) 168.

[23] G. S. Bruno Lebon, H.-T. Li, J. B. Patel, H. Assadi, Z. Fan, Numerical modelling of melt conditioned direct-chill casting, Applied Mathematical Modelling 77 (2) (2020) $1310-1330$. 


\section{Tables:}

\begin{tabular}{|c|c|c|c|}
\hline Alloy & $\begin{array}{l}\text { Casting Speed } \\
(\mathrm{mm} / \mathrm{s})\end{array}$ & $\begin{array}{l}\text { Water Flow } \\
\text { Rate (I/s) }\end{array}$ & $\begin{array}{l}\text { Melt } \\
\text { Temperature in } \\
\text { Launder }\left({ }^{\circ} \mathrm{C}\right) \\
\end{array}$ \\
\hline $\begin{array}{l}\text { AA2011 } \\
\text { (wt. } \% \text { ): } \mathrm{Si}<0.40, \mathrm{Fe}<0.70 \\
\text { Cu } 5.0-6.0, \mathrm{Zn}<0.3 \\
\text { Bi } 0.20-0.6, \mathrm{~Pb}<0.4\end{array}$ & 2.5 & 3 & 685 \\
\hline $\begin{array}{l}\text { AA6050 } \\
\text { (wt.\%): Si } 1.2-1.8, \\
\text { Fe } 1.3-1.8, \text { Cu } 0.15-0.50, \\
\text { Mn } 0.20-0.7, \mathrm{Mg} 0.50-0.90 \text {, } \\
\text { Cr } 0.05-0.25, \\
\text { Ni } 0.2-1.0, \mathrm{Zn}<0.25, \\
\text { Ti }<0.10\end{array}$ & 2.75 & 3 & 700 \\
\hline
\end{tabular}

Table 1: Alloy compositions and casting process parameters.

\begin{tabular}{|c|c|c|c|c|}
\hline Alloy & Melt Treatment & Grain Size $(\boldsymbol{\mu m})$ & DAS $(\boldsymbol{\mu m})$ & Cooling Rate (K/s) \\
\hline AA2011 & DC-GR & $225 \pm 48$ & $21 \pm 4$ & $7.9 \pm 3.7$ \\
\cline { 2 - 5 } & MC-DC & $240 \pm 75$ & $15 \pm 4$ & $19.6 \pm 7.6$ \\
\hline \multirow{2}{*}{ AA6050 } & DC-GR & $280 \pm 83$ & $16 \pm 3$ & $14.2 \pm 5.2$ \\
\cline { 2 - 5 } & MC-DC & $216 \pm 59$ & $12 \pm 2$ & $27.3 \pm 10.5$ \\
\hline
\end{tabular}

Table 2: Grain size, dendritic arm spacing (DAS) and cooling rate at half radius of AA2011 and AA6050 under different melt treatment. The MC-DC cast billets with low DAS show a higher cooling rate indicating enhanced heat extraction. 


\section{Figure Captions:}

Figure 1. Schematic representation of the direct chill casting process showing the melt, slurry and mushy zone. The position of high shear device in the hot top influences the melt temperature, sump profile and eventually the microstructure of the casting alloy.

Figure 2. Scheme of sample cutting showing metallographic samples' positions.

Figure 3. Optical micrographs showing grain structure of DC-GR ((a) edge, (b) half radius, (c) centre) and MC-DC ((d) edge, (e) half radius, (f) centre) of AA2011 cast at $2.5 \mathrm{~mm} / \mathrm{s}$. DC-GR billet shows non uniform grain structure with presence of large floating grains in the centre of the billet. MC-DC billet shows relatively uniform microstructure throughout with finer equiaxed dendritic grains in the half radius.

Figure 4. Optical micrographs showing grain structure of DC-GR ((a) edge, (b) half radius, (c) centre) and MC-DC ((d) edge, (e) half radius, (f) centre) of AA6050 cast at $2.75 \mathrm{~mm} / \mathrm{s}$. DC-GR billet shows presence of floating grains in the centre of the billet. MC-DC billet clearly shows finer and uniform microstructure throughout the billet cross section.

Figure 5. Real sump profile of AA2011 (a) DC-GR and (b) MC-DC cast at $2.5 \mathrm{~mm} / \mathrm{s}$ revealed by adding liquid $\mathrm{Zn}$ during casting: the lighter part shows the solid part of the billet and the darker part shows the sump.

Figure 6. Back scattered electron images from the half radius of AA2011 (a) DC-GR and (b) MC-DC as-cast billets showing distribution of free machining elements (brighter phase, $\mathrm{Pb}, \mathrm{Bi}$ ). The melt treatment by high shear refines the microstructure and improves the distribution of the soft phase particles. 
Figure 7. Complex morphology and network of intermetallics (light and dark grey) in deep etched AA6050 samples from half radius; (a) DC-GR and (b) MC-DC. DC-GR shows larger cell size whereas MC-DC sample revealed finer cells and densely populated intermetallics.

Figure 8. Back scattered electron images near the edge of extruded AA2011 T8 (a) DC-GR and (b) MC-DC sample showing distribution of secondary phases (brighter phase, $\mathrm{Pb}, \mathrm{Bi}$ ) and intermetallics (grey phase). The melt treatment by high shear refines the microstructure and improves the distribution of the soft phase particles.

Figure 9. Histogram showing size distribution of free machining soft phase droplets in AA2011 (a) DC-GR and (b) MC-DC extruded T8 samples. MC-DC sample shows more finer droplets compared to DC-GR sample.

Figure 10. Histogram showing size distribution of intermetallics in AA6050 (a) DC-GR and (b) MC-DC extruded T6 samples. MC-DC sample shows more finer intermetallics compared to DC-GR sample.

Figure 11. Machinability in terms of chip weight at a cutting speed of $2.35 \mathrm{~m} / \mathrm{s}$ and depth of cut of $2 \mathrm{~mm}$ for (a) AA2011 and (b) AA6050. MC-DC extruded AA2011 T8 and AA6050 T6 samples. A large number of chips per $100 \mathrm{~g}$ for MC-DC samples indicates considerable increase in chip breakability compared to DC-GR sample.

Figure 12. Comparison of tensile stress-strain curves of AA6050 extruded T6 samples at room temperature. MC-DC sample shows relatively higher elongation. 


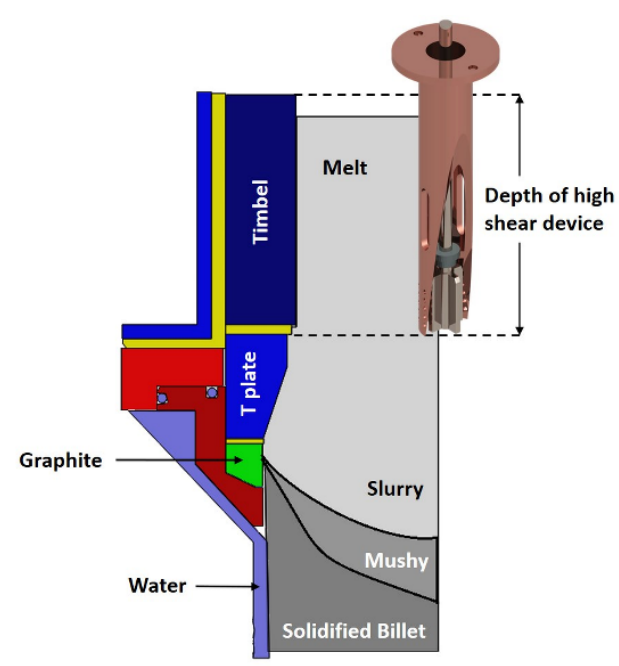

Figure 1. Schematic representation of the direct chill casting process showing the melt, slurry and mushy zone. The position of high shear device in the hot top influences the melt temperature, sump profile and eventually the microstructure of the casting alloy.

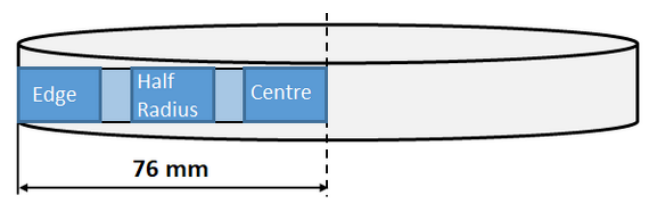

Figure 2. Scheme of sample cutting showing metallographic samples positions. 

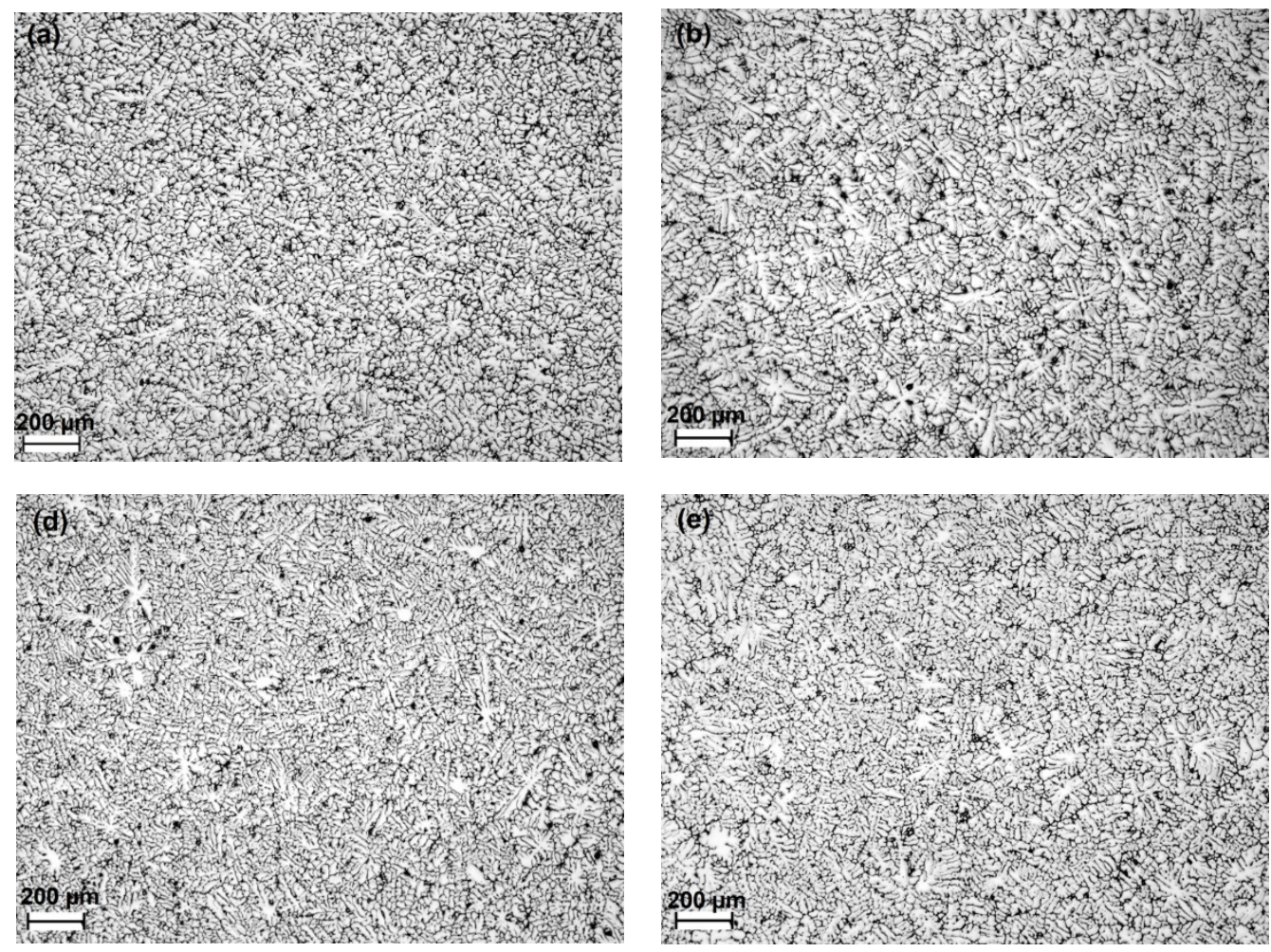

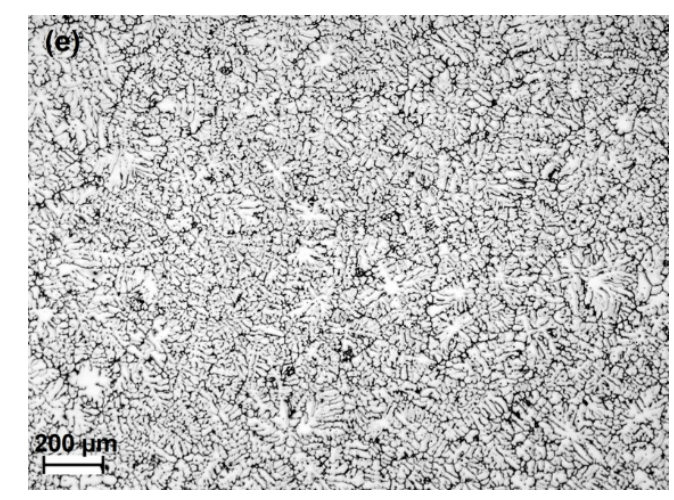

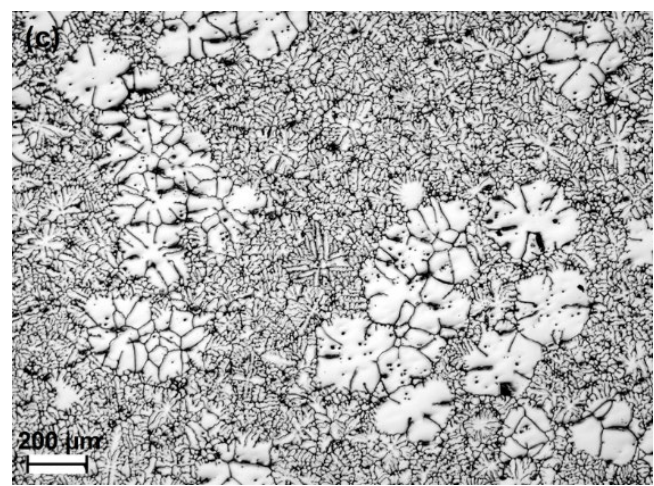

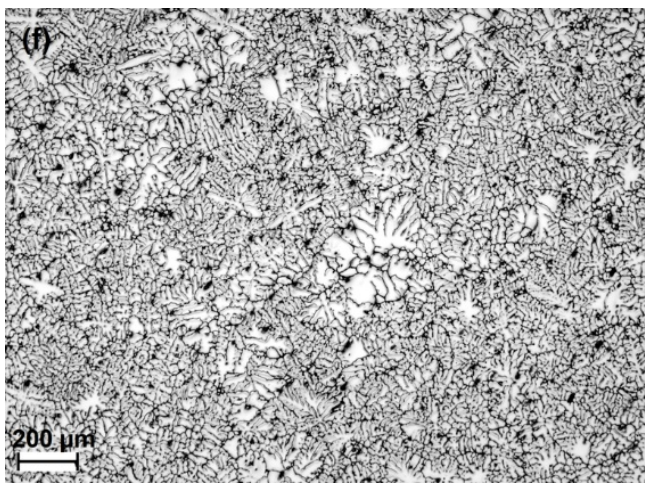

Figure 3. Optical micrographs showing grain structure of DC-GR ((a) edge, (b) half radius, (c) centre) and MC-DC ((d) edge, (e) half radius, (f) centre) of AA2011 cast at $2.5 \mathrm{~mm} / \mathrm{s}$. DC-GR billet shows non uniform grain structure with presence of large floating grains in the centre of the billet. MC-DC billet shows relatively uniform microstructure throughout with finer equiaxed dendritic grains in the half radius. 

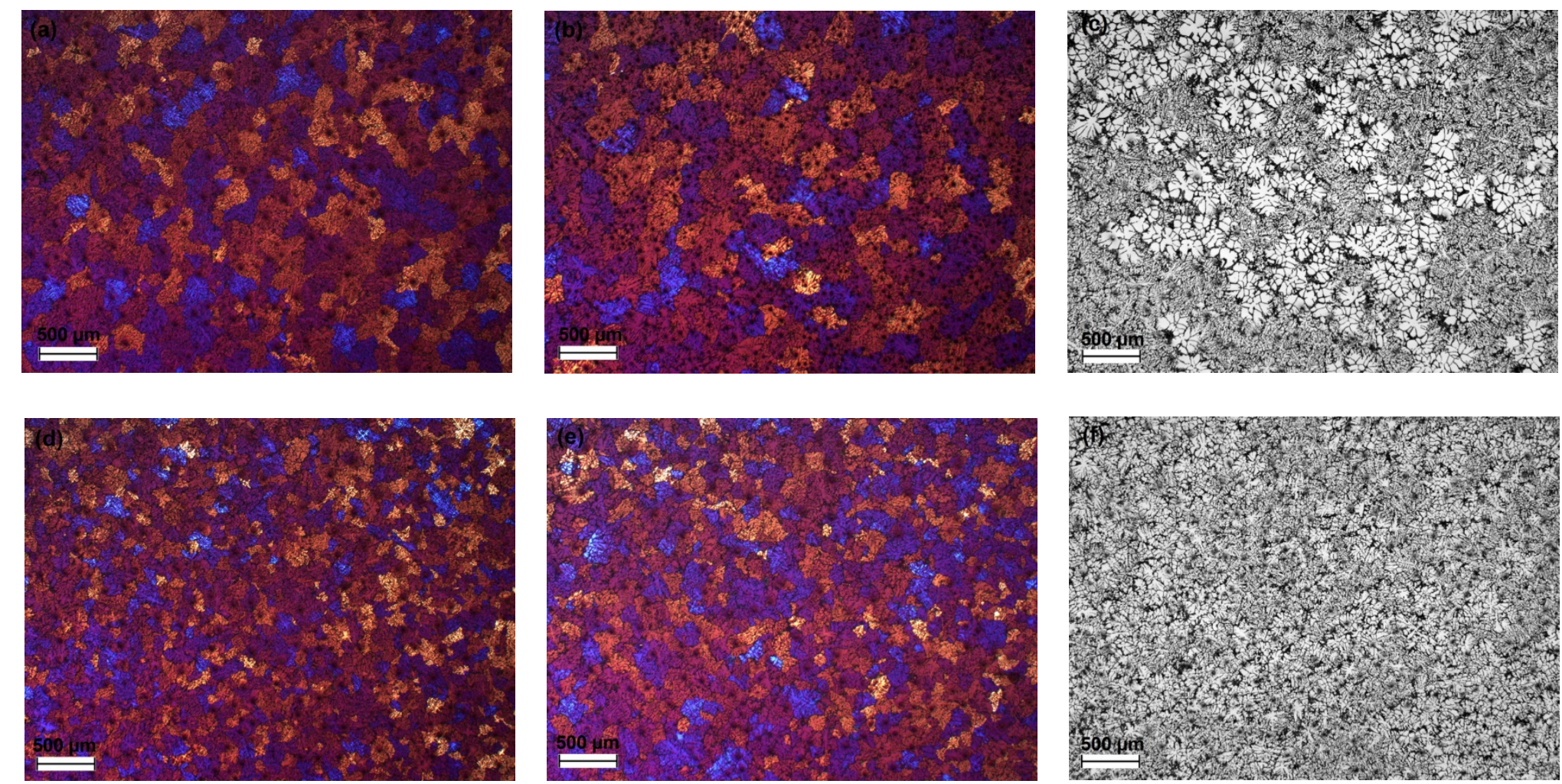

Figure 4. Optical micrographs showing grain structure 'of DC-GR ((a) edge, (b) half radius, (c) centre) and MC-DC ((d) edge, (e) half radius, (f) centre) of AA6050 cast at $2.75 \mathrm{~mm} / \mathrm{s}$. DC-GR billet shows presence of floating grains in the centre of the billet. MC-DC billet clearly shows finer and uniform microstructure throughout the billet cross section.
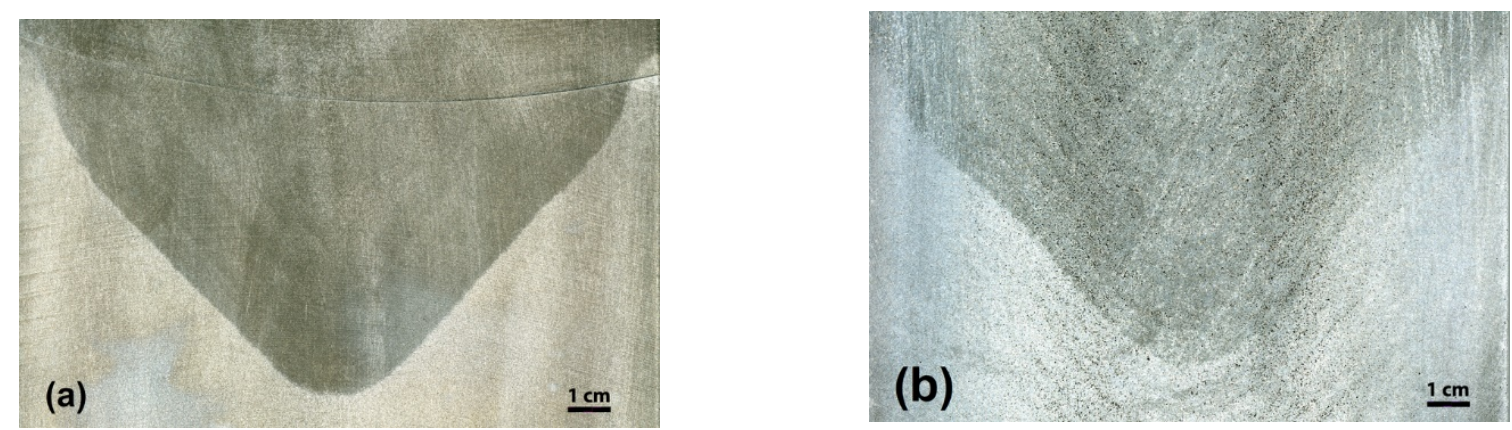

Figure 5. Real sump profile of AA2011 (a) DC-GR and (b) MC-DC cast at $2.5 \mathrm{~mm} / \mathrm{s}$ revealed by adding liquid $\mathrm{Zn}$ during casting: the lighter part shows the solid part of the billet and the darker part shows the sump. 

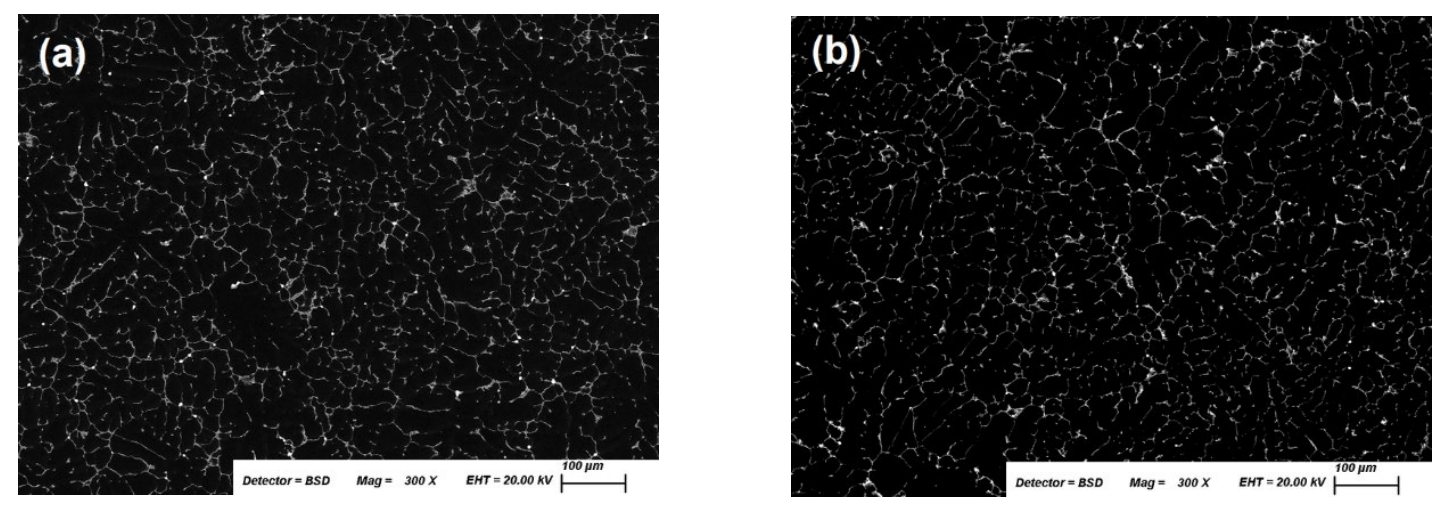

Figure 6. Back scattered electron images from the half radius of AA2011 (a) DC-GR and (b) MC-DC as-cast billets showing distribution of free machining elements (brighter phase, $\mathrm{Pb}, \mathrm{Bi}$ ). The melt treatment by high shear refines the microstructure and improves the distribution of the soft phase particles.
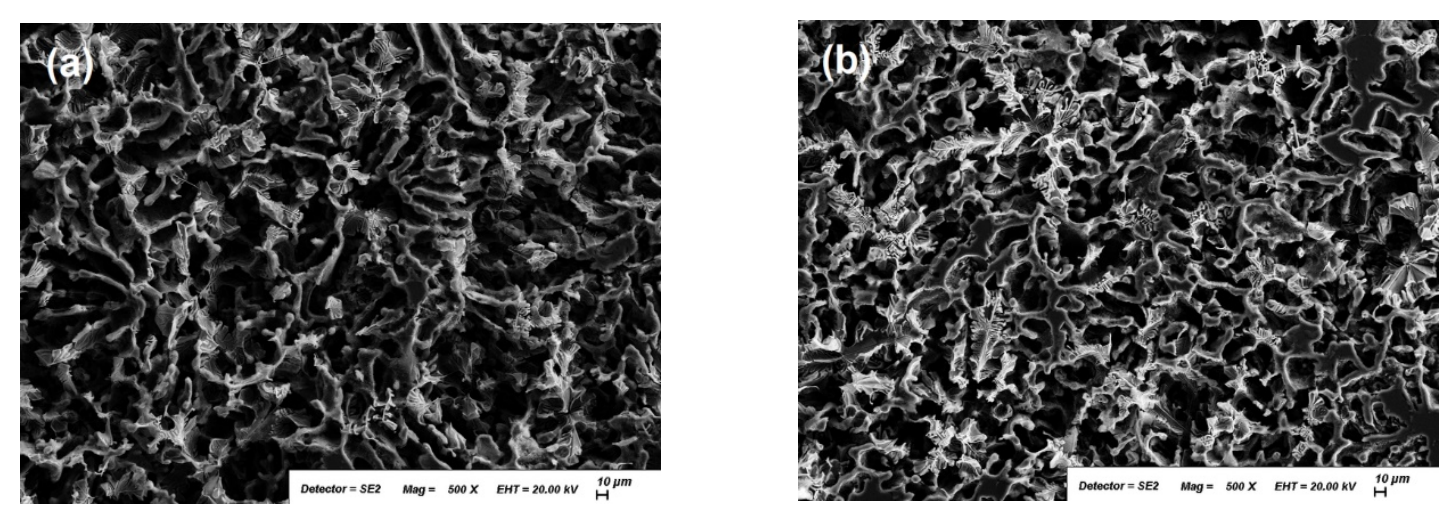

Figure 7. Complex morphology and network of intermetallics (light and dark grey) in deep etched AA6050 samples from half radius; (a) DC-GR and (b) MC-DC. DC-GR shows larger cell size whereas MC-DC sample revealed finer cells and densely populated intermetallics. 

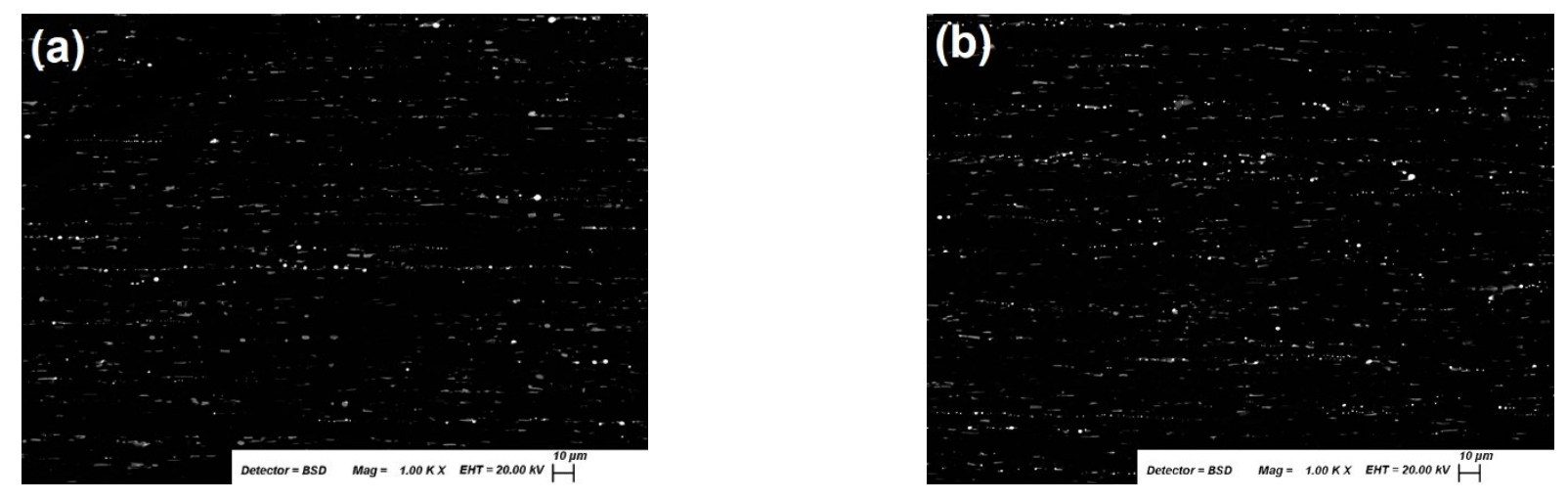

Figure 8. Back scattered electron images near the edge of extruded AA2011 T8 (a) DC-GR and (b) MC-DC sample showing distribution of secondary phases (brighter phase, $\mathrm{Pb}, \mathrm{Bi}$ ) and intermetallics (grey phase). The melt treatment by high shear refines the microstructure and improves the distribution of the soft phase particles.
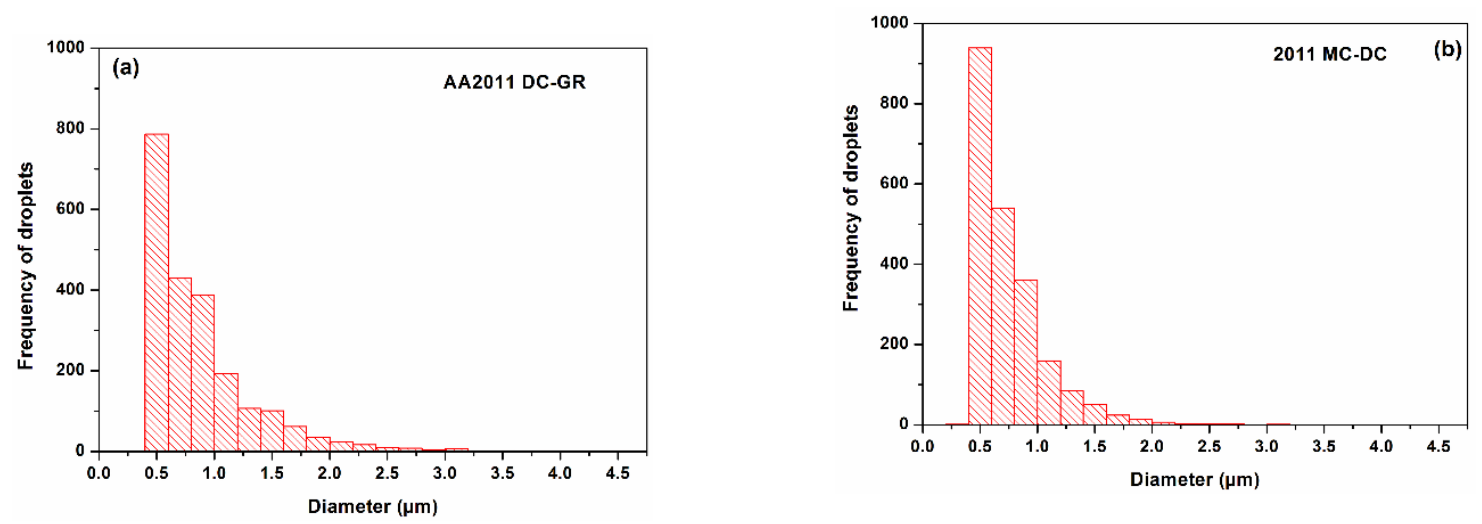

Figure 9. Histogram showing size distribution of free machining soft phase droplets in AA2011 (a) DC-GR and (b) MC-DC extruded T8 samples. MC-DC sample shows more finer droplets compared to DC-GR sample. 

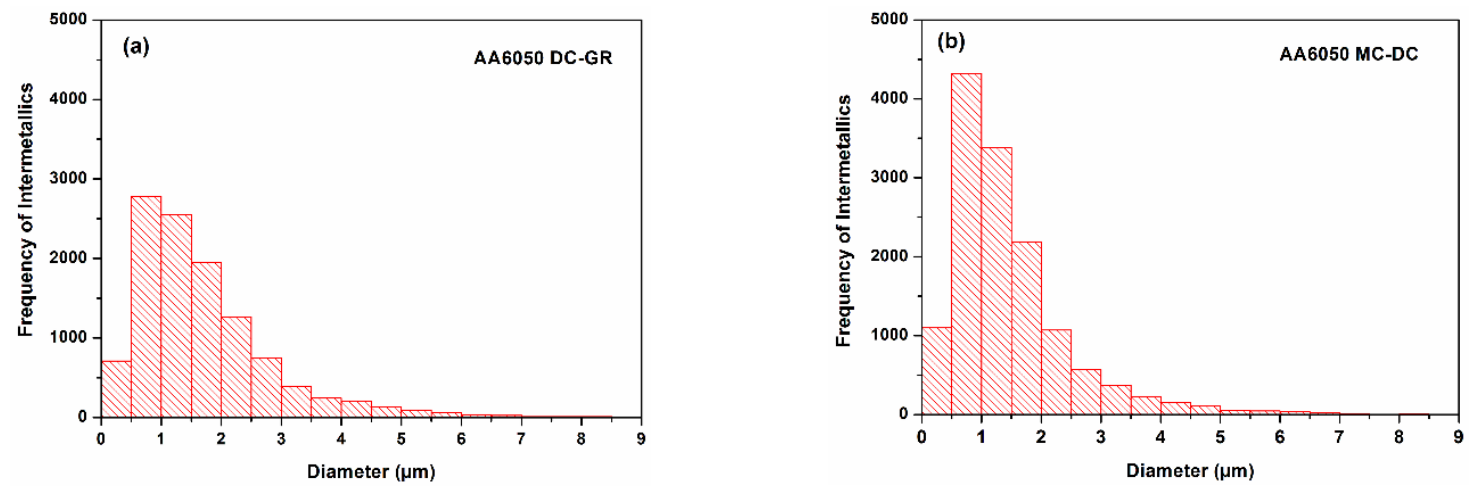

Figure 10. Histogram showing size distribution of intermetallics in AA6050 (a) DC-GR and MC-DC extruded T6 samples. MC-DC sample shows more finer intermetallics compared to DC-GR sample.
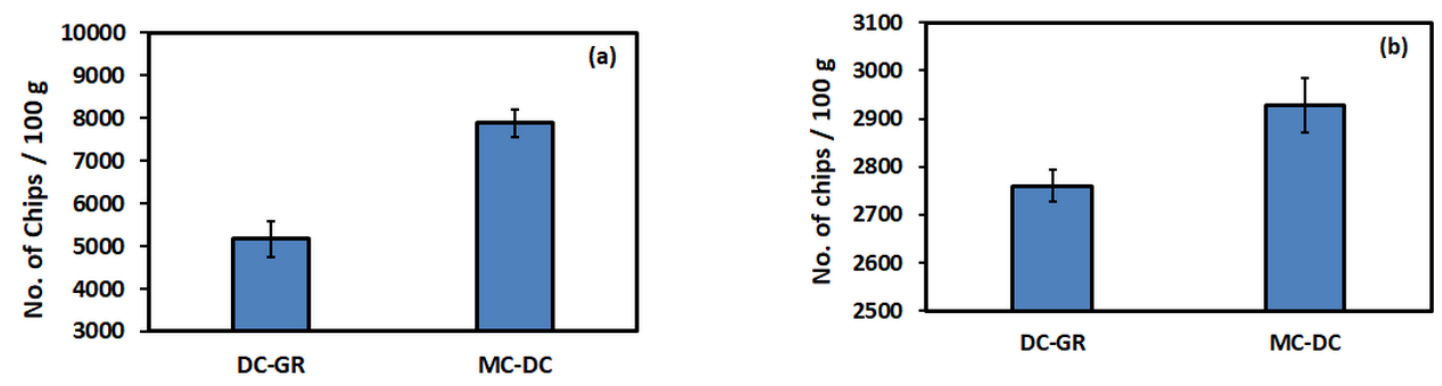

Figure 11. Machinability in terms of chip weight at a cutting speed of $2.35 \mathrm{~m} / \mathrm{s}$ and depth of cut of $2 \mathrm{~mm}$ for (a) AA2011 and (b) AA6050. MC-DC extruded AA2011 T8 and AA6050 T6 samples. A large number of chips per $100 \mathrm{~g}$ for MC-DC samples indicates considerable increase in chip breakability compared to DC-GR sample. 


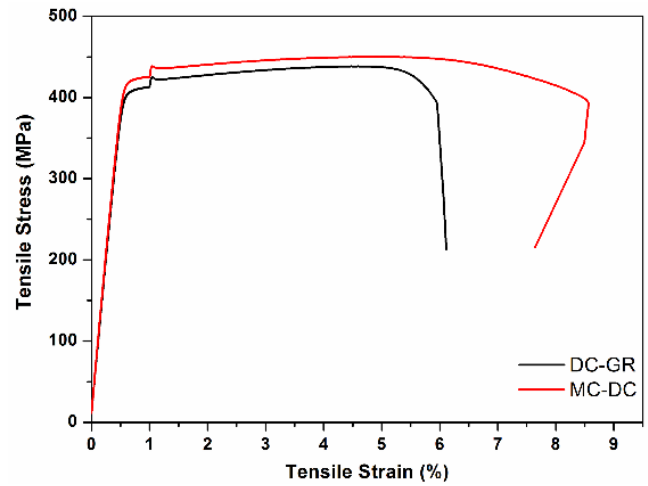

Figure 12. Comparison of tensile stress-strain curves of AA6050 extruded T6 samples at room temperature. MC-DC sample shows relatively higher elongation. 